\title{
Impact of a Mechanical Massage on Gene Expression Profile and Lipid Mobilization in Female Gluteofemoral Adipose Tissue
}

\author{
Marie-Adeline Marques ${ }^{a, b} \quad$ Marion Combes $^{a, b} \quad$ Balbine Roussel $^{a, b} \quad$ Laurence Vidal-Dupont $^{c}$ \\ Claire Thalamas ${ }^{a, d} \quad$ Max Lafontan $^{a, b} \quad$ Nathalie Viguerie ${ }^{a, b}$ \\ ${ }^{a}$ Inserm, UMR 1048, Obesity Research Laboratory, Cardiovascular and Metabolic Medicine Institute, \\ b IFR150, Biomedical Research Federative Institute of Toulouse, Paul Sabatier University, University of Toulouse, Toulouse, \\ ${ }^{\mathrm{c}}$ Physiotherapy Center, Saint-Orens de Gameville, \\ ${ }^{d}$ Clinical Investigation Center Inserm CIC-9302, University Hospital Centre of Toulouse, France
}

\section{Keywords}

Gene expression profiling · Femoral adipose tissue · Isoproterenol-induced lipolysis .

Microdialysis . Adipose tissue blood flow

\section{Summary}

Background: Gluteofemoral adipose tissue areas are known to be poorly metabolically reactive. Mechanical massage has previously been reported to show morphological and functional impact on this tissue. The present study was carried out to delve more deeply into the mechanistic considerations regarding the incidence of a mechanical massage technique on gene expression profile and $\beta$-adrenergic-mediated lipid mobilization in female femoral adipose tissue. Methods: Twelve premenopausal healthy women were included and received 12 sessions of calibrated mechanical massage (Endermologie $^{\circledR}$ ). Total RNA was extracted from femoral adipose tissue biopsies for gene expression studies. Microdialysis was carried out in the femoral adipose tissue in order to assess lipolytic responsiveness (via glycerol determination) and changes in local blood flow following perfusion of a lipolytic agent, isoproterenol. Evaluations were performed before and after the 6-week experimental period. Results: Mechanical massage initiated important modifications in gene expression profile. The lipid-mobilizing effect of isoproterenol was enhanced after the experimental period. Basal local blood flow and isoproterenolinduced vasodilatation were also improved. Conclusion: The protocol of mechanical massage used in the study promoted noticeable changes in the expression of genes involved in metabolic pathways. The lipolytic and local adipose tissue blood flow responses initiated by isoproterenol were significantly enhanced.

\section{Introduction}

Body fat distribution is an important metabolic and cardiovascular risk factor. Several studies have revealed that obesityrelated health risks depend on the accumulation of abdominal and visceral fat. Studies on adipose tissue biology and physiology have shown that striking differences exist regarding fatty acid uptake mechanisms and lipolytic responsiveness between visceral and gluteofemoral fat. Differential adipose tissue blood flow responsiveness has also been reported between fat deposits. Visceral adipose tissue adipocytes are considered to be the smallest and the most responsive to lipid-mobilizing hormones while subcutaneous gluteofemoral adipose tissue (GAT) adipocytes are known to be less metabolically reactive [1]. Fat cell hypertrophy is currently observed in GAT. Moreover, the existence of veno-lymphatic disorders in gluteofemoral fat deposits has been mentioned. A protective role of gluteofemoral body fat has been suggested in subjects with metabolic syndrome and related comorbidities [2-5]. Nevertheless, GAT is often removed by liposuction in normal weight or slightly overweight healthy women by plastic sur-

\section{KARGER \\ Fax +497614520714 \\ Information@Karger.de}

www.karger.com (c) 2011 S. Karger GmbH, Freiburg

$1662-4025 / 11 / 0042-0121 \$ 38.00 / 0$

Accessible online at:

www.karger.com/ofa
Dr. Nathalie Viguerie

Inserm UMR 1048, Obesity Research Laboratory

Cardiovascular and Metabolic Medicine Institute

1 avenue Jean Poulhès, 31432 Toulouse cedex 4 , France

Tel. +33 561-325631, Fax -325623

nathalie.viguerie@inserm.fr 
Fig. 1. Diagram summarizing the design of the study.

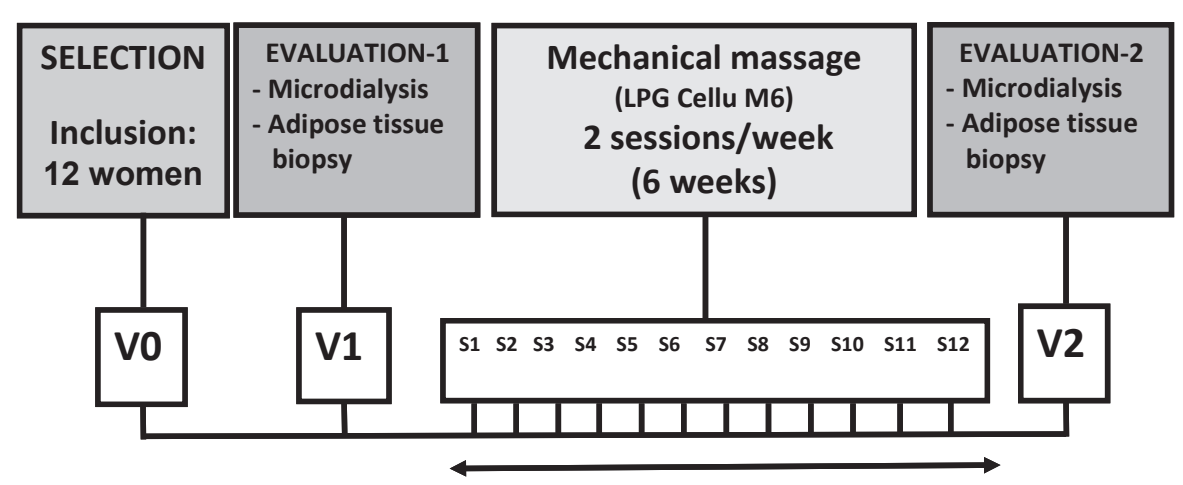

6 weeks geons with the aim of reducing localized fat mass for cosmetic purposes. These women often possess a gynoid morphotype with a low waist/hip ratio. In addition, a number of poorly validated superficial or more invasive techniques such as injection of agents with detergent effects $[6,7]$ or laser-assisted devices [8] have been claimed to impact on this tissue. These various practices could have deleterious effects and require evaluation for their safety and/or efficacy using common explorations of adipose tissue function. A non-invasive technique of calibrated mechanical massage, known to exert some circulatory and dermotrophic effects [9-12], has been shown to reduce body circumferences, skinfold measurements, and cellulite [12-15]. Despite a first attempt to study the impact of the mechanical massage on GAT [15], a clear risk-benefit assumption cannot be easily made in the absence of biological or physiological studies.

Experiments were planned to study the impact of the massage on gene expression profiles using high-throughput gene expression methods. In addition, modifications in isoproterenol-induced lipid mobilization and blood flow changes were studied using in situ microdialysis before and after 12 sessions of calibrated mechanical massage.

Global transcriptional profiling was performed using whole transcriptome microarrays. Human tissue gene expression profiling is now widely used in health research $[16,17]$. This large-scale, a priori-free approach allows the discovery of unsuspected biological processes and molecular networks with novel molecular players. Many studies focused on adipose tissue genome-wide investigations during nutritional challenges [18] and provided new molecular biomarkers [19, 20]. Here, the goal was to use such a strategy to capture a comprehensive overview of GAT response to mechanical massage. Lipid mobilization in GAT was monitored by the in situ microdialysis technique. Small microdialysis probes were implanted in GAT in order to continuously monitor glycerol (the marker of lipolytic activity) appearance in the extracellular space. At the same time the probe also delivers a lipolytic agent locally which will stimulate the lipolytic activity of the adipocytes. Using microdialysis prevents the systemic effects of the lipolytic drug infused in the probe. This in vivo and in situ approach allows the study of acute adipose cell responses in their actual milieu through measurement of glycerol output combined with estimation of local blood flow changes, which play an important role for the regulation of lipid mobilization [21]. It has been largely used to reveal the role of $\beta_{1-2^{-}}$and $\alpha_{2}$-adrenergic receptors and the impact of atrial natriuretic peptides in the control of lipid mobilization in human subcutaneous adipose tissues and to compare the lipolytic responsiveness of adipose tissue in lean and obese subjects [21].

\section{Material and Methods}

\section{Subjects}

Twelve healthy Caucasian premenopausal women (mean age: 31.8 years) were recruited at the Toulouse Clinical Investigation Centre, CHU Purpan, Toulouse, France. All the women had a gynoid morphotype with the following characteristics: height $1.60 \mathrm{~m}$ (95\% confidence interval (CI): 1.60-1.70); weight: $70.7 \mathrm{~kg}$ (95\% CI: 66.8-74.5); body mass index (BMI): $26.8 \mathrm{~kg} / \mathrm{m}^{2}$ (95\% CI: 26.0-27.5); waist/hip ratio: 0.80 (95\% CI: 0.79-0.82). All of them were apparently healthy with normal plasma biological parameters and were under contraceptive treatment. Exclusion criteria included diabetes, pregnancy, hypertension, dyslipidemia, treatment with antidepressants, and use of weight loss drugs. All subjects were told to maintain their usual diet for the total duration of the study. None were engaged in physical activity training programs or calorie restriction protocols. Investigations were approved by the Ethics Committee of Toulouse University Hospitals, and all subjects gave written informed consent.

\section{Study Design}

The design of the study is summarized in the diagram depicted in figure 1. Recruitment of patients, GAT biopsies, and microdialysis experiments were performed at the Clinical Investigation Centre, CHU Purpan, Toulouse, France. Biochemical determinations and transcriptome analyses were performed in the Obesity Research Laboratory, CHU Rangueil, Toulouse, France.

\section{Mechanical Massage Schedule}

Mechanical massage technique (Endermologie ${ }^{\circledR}$ ) was performed by an expert physiotherapist well-experienced in the optimized utilization of the massage device. Each subject received a total of twelve 30-min sessions (two times per week) of mechanical massage (fig. 1). The massage device consisted of a treatment head in which two independently motorized rollers are combined with a suction system allowing multiple mobili- 
zations of the cutaneous and subcutaneous tissues (Cellu M6; LPG Systems, Valence, France). Since investigations dedicated to morphometry (i.e. circumference and cutaneous fold measurements before and after treatment) have been reported in a previous study [15], the present one was focused on biological responses. Morphometry determinations were considered to be out of the scope of the protocol.

\section{GAT Biopsy and Total RNA Preparation}

GAT biopsies were obtained by needle aspiration under local anesthesia after an overnight fast and stored at $-80^{\circ} \mathrm{C}$ until the end of the program. Total RNA from frozen biopsies were prepared as previously described [22], using the RNeasy total RNA Mini kit (Qiagen, Courtaboeuf, France). Total RNA concentration and RNA quality were estimated by capillary electrophoresis using the Experion analyzer (BioRad, Marnesla-Coquette, France).

\section{Probe Labeling and Microarray Analysis}

Target RNA was generated from $500 \mathrm{ng}$ of total RNA with the Agilent low RNA input amplification kit (Agilent Technologies, Massy, France). $\mathrm{Cy} 3$ (before) and Cy5 (after the 12 sessions) probes from the same subject were purified and hybridized to whole genome $4 \times 44 \mathrm{k}$ oligonucleotide arrays (Agilent Technologies), as described in [19]. Data acquisition was performed with an InnoScan 700 scanner (Innopsys, Carbonne, France) and images were processed with Mapix software (Innopsys). Hybridization was quality checked using control spikes. Outlier replicates and spots with a signal-to-noise ratio less than 2 on both red and green channels were eliminated from the analyses, resulting in 18,466 exploitable spots. Log ratio data were normalized with a global Loess procedure and filtered with the R package LIMMA (Bioconductor). Principal component analysis was used to check that all microarray experiments provided consistent data. Differential genes were searched using the one-class Significance Analysis of Microarray (SAM) procedure [23]. Functional analysis was done using Ingenuity Pathway Analysis (IPA) version 8.6 [24] with the Agilent whole genome set as reference.

\section{Real-Time Quantitative PCR}

Reverse transcription (RT) was performed using $1 \mu \mathrm{g}$ of total RNA, random hexamers, and poly(dT) according to the High Capacity cDNA Reverse Transcription Kit (Applied Biosystems, Foster City, CA, USA) [19]. TaqMan ${ }^{\circledast}$ Assays (Applied Biosystems) were used with 18S (Taqman ${ }^{\circledR}$ Control Assays; Applied Biosystems) for gene expression normalization

\section{Microdialysis Experiments}

Subjects were investigated at 8:00 a.m. after an overnight fast, before and after the last mechanical massage session. After light epidermal anaesthesia (Emla ${ }^{\circledR}$ patch 5\%; AstraZeneca, Rueil-Malmaison, France, 20 min, and $200 \mu \mathrm{l}$ of $1 \%$ lidocaine; Roger-Bellon, Neuilly-sur-Seine, France), one microdialysis probe $(20 \times 0.5 \mathrm{~mm}, 20-\mathrm{kDa}$ molecular-weight cut-off; CMA Microdialysis, Solna, Sweden) was inserted percutaneously into GAT at two-thirds of the distance between patella and the superior anterior iliac spine. A contralateral probe was inserted at an equivalent location in the other leg to determine control values (in the absence of a lipolytic agent). The probes were connected to a microinjection pump and continuously perfused with a sterile Ringer solution ( 154 mmol sodium, $6 \mathrm{mmol}$ potassium, $2.5 \mathrm{mmol}$ calcium, $160 \mathrm{mmol}$ chloride). Based on the results of previous studies [25, 26], the perfusion was set at a flow rate of $2 \mu \mathrm{l} / \mathrm{min}$ and fractions were collected following a 30-min equilibration period. After fractions were collected for definition of baseline values, one probe was infused with increasing concentrations of the $\beta$-adrenergic receptor agonist isoproterenol $(0.1,1$, and $10 \mu \mathrm{mol}$, in Ringer solution). The other probe was parallelly infused in Ringer solution alone. Ethanol $(1.7 \mathrm{~g} / \mathrm{l})$ was added to the perfusate in order to estimate changes in the adipose tissue blood flow (ATBF), as previously described [25]. This validated method does provide information on changes in ATBF occurring

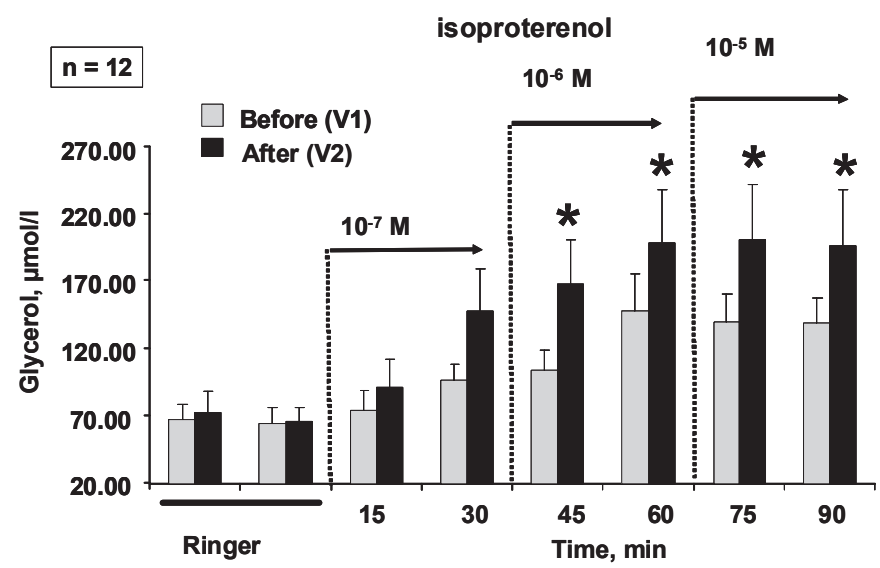

Fig. 2. Changes in isoproterenol-induced glycerol release in GAT induced by repeated mechanical massages. * $\mathrm{p}>0.05$ when compared with values obtained in control conditions (before mechanical massage).

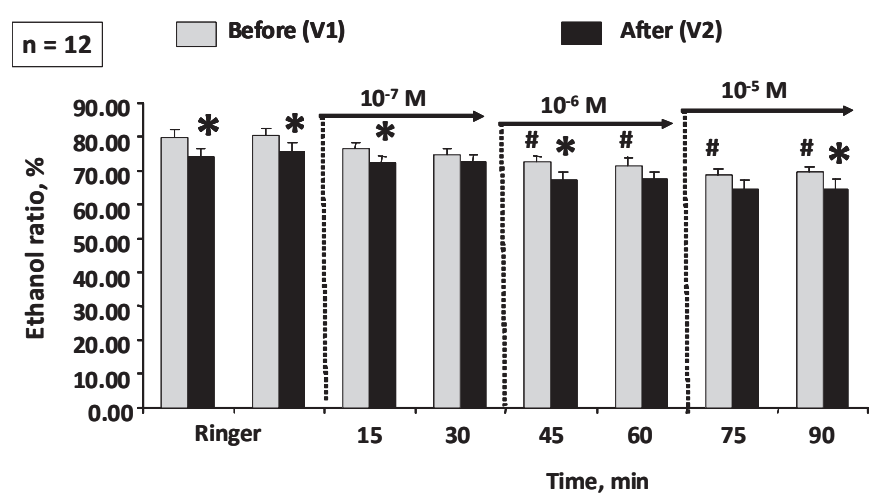

Fig. 3. Isoproterenol-induced changes in gluteofemoral adipose tissue blood flow after repeated mechanical massages. The mean outflow-toinflow ethanol ratio was calculated in percent ratio of the ethanol concentration measured in the dialysate divided by the ethanol concentration measured in the perfusate $\times 100$. \#p $<0.05$ when compared with basal (Ringer) values; *p $<0.05$ when compared with values obtained in control conditions (before mechanical massage).

during the perfusion of pharmacological agents or in some physiological conditions. The mean outflow-to-inflow ethanol ratio was calculated in percent ratio of the ethanol concentration measured in the dialysate divided by the ethanol concentration measured in the perfusate $\times 100$ and taken as an index of ethanol washout. Dialysate fractions were collected for each concentration as indicated in figures 2 and 3. Ethanol was measured immediately while fractions for glycerol determination were frozen and stored at $-80^{\circ} \mathrm{C}$ until dosage at the end of the program.

\section{Biochemical Determinations}

Glycerol in dialysate was analyzed by an enzymatic method (Sigma, Saint Louis, MO, USA), as previously described [26]. The intra-assay coefficient of variation $(\mathrm{CV})$ was $7.6-8.0 \%$ and the interassay $\mathrm{CV}$ was $8.8-9.6 \%$. Ethanol in dialysate and perfusate $(5 \mu \mathrm{l})$ was determined with an enzymatic method [27]. The intra- and interassay CV was $3.0 \%$ and $4.5 \%$, respectively.

\section{Conventional Statistical Analysis}

All values of lipolytic assays are presented as means \pm SEM. Statistical analysis was performed using SPSS for Windows 17.0 (SPSS Inc, Chicago, IL, USA). Results from non-parametric paired Wilcoxon test were considered significant if $\mathrm{p}<0.05$. 
Table 1. Top 20 regulated genes

\begin{tabular}{|c|c|c|}
\hline Gene symbol & $\begin{array}{l}\text { Mean fold } \\
\text { change }\end{array}$ & Name \\
\hline \multicolumn{3}{|c|}{ Up-regulated genes } \\
\hline SPP1 & 6.9 & secreted phosphoprotein 1 \\
\hline RARRES1 & 6.5 & retinoic acid receptor responder (tazarotene-induced) 1 \\
\hline IL1RN & 5.6 & interleukin 1 receptor antagonist \\
\hline ABCG2 & 5.5 & ATP-binding cassette, sub-family G (WHITE), member 2 \\
\hline MMP7 & 5.3 & matrix metallopeptidase 7 (matrilysin, uterine) \\
\hline CHIT1 & 5.3 & chitinase 1 (chitotriosidase) \\
\hline PLA2G7 & 5.2 & phospholipase A2, group VII \\
\hline AADACL1 & 5.2 & arylacetamide deacetylase-like 1 \\
\hline APOC1 & 5.1 & apolipoprotein C-I \\
\hline EBI2 & 5.0 & G protein-coupled receptor 183 \\
\hline EGR2 & 4.4 & early growth response 2 \\
\hline ATP1B1 & 4.3 & ATPase, $\mathrm{Na}+\mathrm{K}+$ transporting, beta 1 polypeptide \\
\hline MMP9 & 4.2 & matrix metallopeptidase 9 \\
\hline PRG4 & 4.1 & proteoglycan 4 \\
\hline RAB11FIP4 & 4.0 & RAB11 family interacting protein 4 (class II) \\
\hline ACP5 & 4.0 & acid phosphatase 5 , tartrate resistant \\
\hline CCL18 & 3.9 & chemokine (C-C motif) ligand 18 \\
\hline DHRS9 & 3.9 & dehydrogenase/reductase (SDR family) member 9 \\
\hline TREM2 & 3.7 & triggering receptor expressed on myeloid cells 2 \\
\hline NLRC4 & 3.7 & NLR family, CARD domain containing 4 \\
\hline \multicolumn{3}{|c|}{ Down-regulated genes } \\
\hline FGD5 & 0.5 & FYVE, RhoGEF and PH domain containing 5 \\
\hline $\mathrm{CD} 63$ & 0.5 & CD63 molecule \\
\hline EEF1A1 & 0.5 & eukaryotic translation elongation factor 1 alpha 1 \\
\hline ZNF409 & 0.5 & zinc finger protein 409 \\
\hline KIAA0831 & 0.5 & KIAA0831 \\
\hline SAA1 & 0.5 & serum amyloid A1 \\
\hline CXorf36 & 0.5 & chromosome $\times$ open reading frame 36 \\
\hline IQCE & 0.5 & IQ motif containing $\mathrm{E}$ \\
\hline C10orf116 & 0.5 & chromosome 10 open reading frame 116 \\
\hline RPLP2 & 0.4 & ribosomal protein, large, $\mathrm{P} 2$ \\
\hline G0S2 & 0.4 & G0/G1switch 2 \\
\hline THRAP2 & 0.4 & mediator complex subunit 13-like \\
\hline CFD & 0.4 & complement factor D (adipsin) \\
\hline RPS20 & 0.4 & ribosomal protein $\mathrm{S} 20$ \\
\hline RAMP2 & 0.4 & receptor ( $\mathrm{G}$ protein-coupled) activity modifying protein 2 \\
\hline RPS28 & 0.4 & ribosomal protein S28 \\
\hline LIPE & 0.4 & lipase, hormone-sensitive \\
\hline CYB5R3 & 0.4 & cytochrome b5 reductase 3 \\
\hline HRASLS3 & 0.4 & phospholipase A2, group XVI \\
\hline C19orf55 & 0.4 & chromosome 19 open reading frame 55 \\
\hline
\end{tabular}

Genes were selected by SAM analysis with a false discovery rate $<0.05$ and filtered for genes with known protein products. Genes have been ranked according to their mean ratio of mRNA levels at V2 divided by values at V1.

\section{Results}

\section{Changes in GAT Gene Expression Profile Induced by}

\section{Repeated Mechanical Massage}

Statistical analyses revealed 2,259 unique differentially expressed transcripts, with changes in expression ranging from 1.2 to 6.9 and 0.9 to 0.4 for up- and down-regulated genes, respectively. Table 1 presents the top 20 up- and down-regu- lated genes in GAT after mechanical massage. Changes in mRNA levels of 23 genes were verified using RT-qPCR in order to validate the microarray data (table 2). Microarray and quantitative PCR data were highly correlated $\left(\mathrm{R}^{2}=0.9198\right)$.

The selection procedure resulted in 1,014 up-regulated and 1,245 down-regulated transcripts, including 691 genes (509 upand 182 down-regulated) with an expression level greater 
than 1.5-fold change. The 1,903 genes with eligible IDs that mapped the IPA database are represented in the supplementary table (at http://content.karger.com/ProdukteDB/produkte. asp? doi=327347).

As indicated in table 3, the top-ranking IPA canonical pathway was 'glycerolipid metabolism', with $73 \%$ of the genes down-regulated. Four other pathways related to metabolism were also significant, 'propranoate metabolism', 'glycolysis/ gluconeogenesis', 'citrate cycle', and 'pyruvate metabolism', which consisted of $81,68,100$, and $73 \%$ of down-regulated genes, respectively, as indicated in figure 4.

The IPA ontology also selected the lists 'mitochondrial dysfunction' and four signal transduction pathways with more than two thirds of the genes being down-regulated, except the one for 'chemokine signaling' which contained two thirds of up-regulated genes. The 'apoptosis' and 'acute phase response signaling' lists encompassed quite similar numbers of up- and down-regulated genes (41 and $55 \%$ of genes with higher expression level, respectively).

\section{Changes in Isoproterenol-Induced Glycerol Release in GAT} Induced by Repeated Mechanical Massage

Basal glycerol output obtained during infusion of Ringer solution alone in the control probe was stable during the experimental period. The values of glycerol determined in the control probes were taken into account to calculate glycerol output in stimulated conditions. A concentration-dependent increment of glycerol output was observed during isoproterenol infusion before the treatment (fig. 2). After the mechanical massage sessions, isoproterenol challenges were performed (at least $24 \mathrm{~h}$ ) after the last massage session. Mean values of isoproterenol-induced glycerol output at 1 and $10 \mu \mathrm{mol}$ were significantly increased when compared to the values obtained before the massage sessions (fig. 2).
Isoproterenol-Induced Changes in GAT Blood Flow after Repeated Mechanical Massage

The mean outflow-to-inflow ethanol ratio ((ethanol concentration in dialysate/ethanol concentration in perfusate $) \times 100$ ),

Table 2. Gene expression validation by RT-qPCR

\begin{tabular}{|c|c|c|c|}
\hline Gene symbol & $\begin{array}{l}\text { Microarray } \\
\text { fold change }\end{array}$ & $\begin{array}{l}\text { RT-qPCR } \\
\text { fold change }\end{array}$ & p-value \\
\hline SPP1 & 6.9 & $7.12 \pm 3.28$ & 0.012 \\
\hline MMP9 & 4.2 & $6.68 \pm 2.95$ & 0.019 \\
\hline CTSS & 2.6 & $2.72 \pm 0.90$ & 0.041 \\
\hline CD163 & 2.2 & $2.12 \pm 0.48$ & 0.028 \\
\hline CCR7 & 2.06 & $2.71 \pm 0.59$ & 0.034 \\
\hline SFRP4 & 1.91 & $2.19 \pm 0.54$ & 0.034 \\
\hline DKK3 & 1.9 & $1.73 \pm 0.24$ & 0.010 \\
\hline AQP3 & 1.9 & $2.36 \pm 0.50$ & 0.023 \\
\hline CTSL1 & 1.6 & $1.62 \pm 0.31$ & 0.050 \\
\hline CD44 & 1.5 & $1.35 \pm 0.20$ & 0.158 \\
\hline NRF1 & 1 & $1.03 \pm 0.08$ & 0.875 \\
\hline ATGL & 0.81 & $0.86 \pm 0.08$ & 0.084 \\
\hline GAPDH & 0.81 & $1.11 \pm 0.12$ & 0.754 \\
\hline AQP7 & 0.73 & $0.82 \pm 0.06$ & 0.008 \\
\hline PLAT & 0.73 & $0.74 \pm 0.09$ & 0.019 \\
\hline LEP & 0.73 & $0.84 \pm 0.12$ & 0.158 \\
\hline CIDEC & 0.69 & $0.79 \pm 0.09$ & 0.028 \\
\hline CD36 & 0.68 & $1.00 \pm 0.08$ & 0.638 \\
\hline RARRES2 & 0.65 & $0.74 \pm 0.06$ & 0.003 \\
\hline CES1 & 0.63 & $0.78 \pm 0.12$ & 0.028 \\
\hline RBP4 & 0.54 & $0.88 \pm 0.14$ & 0.158 \\
\hline SAA1 & 0.5 & $0.98 \pm 0.19$ & 0.480 \\
\hline LHS & 0.38 & $0.83 \pm 0.09$ & 0.071 \\
\hline
\end{tabular}

Changes in mRNA levels were determined using microarrays and RT-qPCR before (V1) and after 12 sessions of mechanical massage (V2). Data represent mean \pm SEM (ratio of mRNA levels at V2 divided by values at V1) of 12 subjects.
Table 3. Biological functions associated with differential genes

\begin{tabular}{llccc}
\hline Canonical pathways & $\begin{array}{l}\text { Down-regulated } \\
\text { genes }\end{array}$ & $\begin{array}{l}\text { Up-regulated } \\
\text { genes }\end{array}$ & $\begin{array}{l}\text { Reference } \\
\text { genes }\end{array}$ & p-value \\
\hline Glycerolipid metabolism & 16 & 6 & 96 & 0.002 \\
Mitochondrial dysfunction & 17 & 9 & 130 & 0.002 \\
Propanoate metabolism & 13 & 3 & 64 & 0.005 \\
Glycolysis/gluconeogenesis & 13 & 6 & 90 & 0.008 \\
PI3K/AKT signaling & 16 & 6 & 127 & 0.010 \\
PTEN signaling & 13 & 5 & 100 & 0.013 \\
ERK/MAPK signaling & 20 & 10 & 187 & 0.013 \\
Citrate cycle & 9 & 0 & 30 & 0.014 \\
Apoptosis signaling & 10 & 7 & 87 & 0.019 \\
Chemokine signaling & 5 & 4 & 71 & 0.020 \\
Pyruvate metabolism & 11 & 15 & 73 & 0.020 \\
Acute phase response signaling & 12 & 4 & 95 & 0.026 \\
IGF-1 signaling & 12 & & 95 & 0.036 \\
\hline
\end{tabular}

Significant biological functions of differential genes were defined by the IPA (Ingenuity Systems; www.ingenuity.com). Benjamini-Hochberg correction was applied for multiple testing. The threshold for statistical significance was $\mathrm{p}<0.05$. 


Percentage
Citrate cycle
Propranoate metabolism
Chemokine signaling
Glycolysis/gluconeogenesis
Pyruvate metabolism
Mitochondrial dysfunction
Apoptosis signaling
PTEN signaling
PI3K/AKT signaling
ERK/MAPK signaling
IGF1 signaling
Acute phase response signaling

Fig. 4. Functional categorization of differentially expressed genes. Biological processes significantly overrepresented among the list of repeated mechanical massage-responsive GAT genes were assessed using IPA. Ingenuity's Pathways Knowledge Base was seeded with the gene symbols together with the array mean fold change of the differentially expressed genes. A Benjamini-Hochberg multiple testing correction p-value was applied to the 1,903 eligible gene symbols of the dataset. Pathways with p-value $<0.05$ are represented. Stacked bar charts indicate the percentage of genes regulated by the massages relative to the total number of genes in the reference dataset. Black bars indicate up-regulated genes and grey bars down-regulated genes.

an indicator of ethanol washout in GAT, was used for an evaluation of the changes in ATBF; the higher the ratio, the lower the ATBF (fig. 3). In basal conditions the higher ethanol ratio value indicates that ATBF is low in GAT. Isoproterenol promoted a concentration-dependent reduction of the ethanol ratio assessing an increment of ethanol washout and occurrence of a vasodilatation. After the mechanical massage sessions, the ethanol ratio was significantly reduced in basal conditions (i.e. preinfusion values were significantly lower; $\mathrm{p}<0.05)$. Moreover, isoproterenol-induced decrease in outflow-to-inflow ethanol ratio was significantly increased after the mechanical massage (fig. 3). This steady-state was maintained all along the infusion of isoproterenol.

\section{Discussion}

The major findings of this study are that chronic treatment of female GAT with a mechanical massage device promoted noticeable changes in the expression of a number of genes involved in pathways related to metabolism. Moreover, an enhancement of both the lipolytic responsiveness of GAT and ATBF were also revealed when compared with the control responses obtained before treatment.

The adipose tissue exhibits distinct morphological and metabolic properties regarding anatomical localization and whole body metabolic status. Transcriptomics has been widely used to examine the effects of physiological and nutritional challenges on adipose tissue gene expression [18, 28]. Tissue mechanical stretch has been studied in cardiomyocytes [29] and skeletal muscle especially in the context of exercise [30], but studies on adipose tissue are scarce. Up to now, no largescale study has focused on the effects of mechanical challenges on human GAT.

In the present study, the number of differential genes and the range of gene expression changes were in agreement with those obtained in subcutaneous adipose tissue during nutritional challenges $[19,22,31]$. Thirteen biological processes were significantly altered by the mechanical massage.

We first focused on the pathways with noticeable unbalance between up- and down-regulated genes. Among them, six were closely related to metabolism and significantly enriched. Four were part of the carbohydrate metabolism. Regarding glycolysis, all genes but two were repressed. Those encoding fructose-1,6-bisphosphatase 1 and pyruvate kinase were indeed up-regulated. All genes for citrate cycle were down-regulated. The other significant metabolic pathway encompassed genes encoding proteins with key function in glycerolipid metabolism, especially triglyceride metabolism. Indeed, the three genes for the enzymatic part of lipolysis [32], LIPE, ATGL, and MGL, as well as two genes encoding proteins involved in fatty acid entry, CD36 and LPL, were down-regulated. Triglyceride synthesis also appeared lowered with downregulation of many genes, including DGAT2 which encodes a crucial enzyme for glycerolipid synthesis [33]. In addition, many genes encoding proteins involved in the synthesis of acetyl-CoA, the activated form of fatty acids for triglyceride synthesis, were repressed. The down-regulation of five genes for the inner mitochondrial membrane complex I, four for complex II, and two for complex IV indicated a lowered energy metabolism potential. Of note is that we previously showed a hypometabolic state during a longitudinal weight loss program with shutdown of fatty acid, glycolytic, and energy metabolism pathways [19]. However, the nature of the genes regulated in the present study is not strictly comparable, while the location of adipose tissue (femoral vs. abdominal) and the population studied (overweight vs. obese women) were also different. The phosphoinositide 3-kinase (PI3K)/Akt and tensin homologue (Pten) pathways were also significantly enriched. These pathways shared common genes with the chemokine and the IGF1 signaling as they included many genes of membrane or intracellular transduction signal for various cytokines and growth factors. Altogether, these four pathways did not provide evidence for any biological impact despite a predominance of down-regulated genes. A key role of the ERK/MAPK system in the response to cyclic stretching has been demonstrated in 3T3-L1 murine adipocytes [34]. In this study, activation of the ERK/MAPK pathway blunted PPAR $\gamma 2$ expression, leading to an inhibition of differentiation. Wnt/ $\beta$ catenin signaling is also a well-known inhibitory of adipogenesis [35]. Here, on the one 
hand, the tendency of gene expression towards a slowdown of ERK pathway together with the up-regulation of the antagonist of Wnt signaling, dickkopf-related protein 3 (DKK3) may indicate a proadipogenic effect. On the other hand, the downregulation of the key transcription factor for adipocyte differentiation PPAR $\gamma$ [36] hampers any clear-cut conclusion regarding adipogenesis.

Massage is known to grab the attachments below the skin, leading to modifications of connective tissue. Surprisingly, no functional pathway related to fibrosis was found significantly enriched despite up-regulation of fibronectin, many peptidases (four metalloproteinases being up- and one down-regulated), and seven cathepsins with enhanced expression level [37]. Ten collagen isoforms had higher but four showed lower expression levels. Both isoforms 1 and 2 of TGF- $\beta$ were overexpressed [37], but the profibrotic osteonectin [1] was downregulated. However, when compared to the total number of genes annotated as related to fibrosis in the reference dataset, these genes did not account for a statistically significant change in this particular pathway. Besides the 'chemokine signaling' pathway with up-regulated cytokines, chemokines, and their receptors, there was a down-regulation of IL-16 and SAA1 together with an up-regulation of the receptor for the anti-inflammatory cytokine IL-10 (IL-10Ra). IL-1RN encodes an antagonist of the receptor for IL-1, and CD163 is an acute phase-regulated receptor induced by anti-inflammatory and suppressed by proinflammatory mediators. However, this could account for some defense response of the adipose tissue to the massage.

Indeed, gene expression profiling does not account for functionality but one of the major goals of genome-wide investigations is to focus on unsuspected pathways. Here, the most striking effect is the slowdown of metabolism, especially the whole lipolytic cascade.

Before discussing the evaluation of the impact of the mechanical massage treatment on lipid mobilization and ATBF modifications in female GAT, some aspects must be taken into consideration. Lipid mobilization depends on the lipolytic rate of adipocytes as well as on changes in ATBF. In physiological conditions, lipolysis in human adipocytes is mediated by epinephrine and norepinephrine which stimulate both $\alpha_{2}$ - and $\beta_{1-2}$-adrenergic receptors on the fat cell surface. Differences in the responsiveness of female adipose tissue to the adrenergic stimulation are regional and related to the functional balance between fat cell $\alpha_{2}$ - and $\beta$-adrenergic responses [38]. Lipid accretion in the gluteofemoral fat depot is favored by the relatively sluggish catecholamine-induced fat turnover. Increased expression of $\alpha_{2}$-adrenoceptors and concomitant decrease of $\beta$-adrenergic responsiveness occurring with fat cell hypertrophy could be a physiological adaptation that leads to the reduction of the lipolytic responsiveness of the hypertrophied adipocytes of the gluteofemoral deposit. In addition, a weaker ATBF has been described in gluteofemoral fat deposits.
Considering these rather complex responses of GAT to catecholamines, the $\beta$-adrenergic agonist, isoproterenol, was preferred to physiological amines. The present study was designed to test a putative impact of mechanical massage on the sensitivity to a $\beta$-adrenergic receptor agonist using two important indexes, lipolytic response and ATBF changes. As shown in figure 2, the concentration-dependent rise in glycerol in dialysate initiated by isoproterenol is strikingly enhanced after mechanical massage, indicating an improved lipid mobilizing ability in the GAT in agreement with previous observations [15]. Concomitantly, the reduction of ethanol ratio value in basal conditions after mechanical massage suggests an improvement of local ATBF and thus adipose tissue drainage in GAT, a tissue known for its reduced metabolic responsiveness and some veno-lymphatic dysfunctions. A confirmation is provided by the isoproterenol-induced decrease in ethanol ratio values which were also significantly improved after the mechanical massage (fig. 3). Thus, isoproterenol exerts a greater vasodilator effect after the mechanical massage. The mechanisms underlying the increased blood flow cannot be easily approached with the microdialysis method, and our interpretations will remain speculative. It must be considered that local ATBF estimated by the ethanol escape method represent a non-quantitative approach that does not allow the absolute determination of local blood flow rates and mechanistic proposals. In addition, to improve basal and isoproterenol-induced vasodilatating potencies of vessels, occurrence of neoformation of blood vessels after chronic treatments cannot be excluded. When considering gene expression (supplementary table), despite some well-known proangiogenic factors such as angiogenin, angiopoietin1 [39], or leptin [40] were down-regulated, others were markedly up-regulated, such as osteopontin (SPP1) [41]. The angiopoietin receptor TIE1 [42] showed a reduced gene expression. This indicates that gene expression profile of genes involved in angiogenesis and angiogenic factors was not statistically impacted by the repeated mechanical massage sessions.

An important point is that changes occurring in local ATBF can influence glycerol dialysate concentrations and limit the amplitude of the final lipolytic response [43, 44]. The impact of isoproterenol on vessels probably limits the increment in dialysate glycerol values during perfusion due to increased washout. From the results obtained in the present study it can be proposed that mechanical massage improves lipolysis and ATBF responsiveness to isoproterenol in GAT. The increased lipolytic ability in fat cells could be due to changes at the receptor level ( $\beta$-receptor number and/or affinity for isoproterenol or coupling efficiency between $\beta$-receptors, Gs protein, and adenylyl cyclase) and at the post-receptor level (protein kinases, hormone-sensitive and adipose triglyceride lipase amount and/or activity without excluding changes in lipid droplet-associated proteins). Mechanisms mediating a mechanical stimulus such as stretching and rubbing adipose tissue will be very difficult to evalu- 
ate. There are several reports on the effects of mechanical stimuli on differentiation in cell lineages derived from mesenchymal stem cells $[34,45,46]$ while reports on adipogenesis are rare. Mechanical stretching has been shown to inhibit adipocyte differentiation of 3T3-L1 cells [34] and of human preadipocyte cell line, SGBS [45]. However, there is no report concerning the direct effect of mechanical stimulation on human adipocytes or other cells of the stroma-vascular fraction of adipose tissue.

It could be of interest to compare the impact of the changes promoted by 12 sessions of mechanical massage with some previous results which have also reported an increase in $\beta$ adrenergic sensitivity to isoproterenol in the abdominal subcutaneous adipose tissue. An improvement of lipid mobilization has already been demonstrated in obese men during in situ isoproterenol perfusion after a very-low-calorie diet [47, 48]. An increase in sensitivity to isoproterenol has also been reported in obese men after 3 months of training [49]. A 16week endurance training program has been shown to improve the lipid mobilizing effects of isoproterenol and atrial natriuretic peptides administered in situ in the subcutaneous adipose tissue of overweight young men [50]. The beneficial effect of endurance training on $\beta$-adrenergic responsiveness was quite similar to that reported in the present study although gender (men vs. women) and adipose tissue locations (abdominal vs. gluteofemoral) are different.

In conclusion, this study reveals that a calibrated mechanical massage of GAT shows a number of unsuspected impacts on the expression of genes involved in metabolic pathways while having no noticeable impact on fibrosis and apoptotic pathways. From a functional perspective the trend towards decreased metabolism indicates that the metabolic machinery of the adipose tissue was maybe lowered as a feedback re- sponse to an enhanced lipolytic activity. Undeniably, mechanical massage promotes noticeable functional improvements in adipose tissue biology including enhanced lipolytic responsiveness and ATBF. Recovery of a higher lipolytic efficiency in adipose tissue could be an important benefit if associated to physical activity training programs as training enhances both non-esterified fatty acid mobilization from adipose tissue and their oxidation by the skeletal muscle. The indication of a repressed metabolic activity may be taken into account to guide supporting hints in addition to nutritional advices accompanying mechanical massage programs.

\section{Acknowledgement}

We thank Laurent Marquine for technical assistance in adipose tissue biopsies management.

This study was supported by funds provided by LPG Systems, Valence, France, to the Toulouse Clinical Investigation Centre, CIC-9302, Centre Hospitalier Universitaire de Toulouse. LPG Systems had no influence on the design of the study or the analyses and interpretations of the results.

LV-D is the physiotherapist who performed mechanical massage treatments. NV and ML participated in the conception and design of the study and interpretation of the data. NV performed gene expression functional analysis and drafted the final manuscript. CT performed clinical studies, M-AM biochemical analyses, and $\mathrm{MC}$ and BR performed gene expression studies. All the authors have read and agree with the manuscript as written.

\section{Disclosure Statement}

The authors declared no financial interest except ML who received consulting fees for his contribution to the advisory board of the LPG Systems company and to participate in workshops organized by the company.

\section{References}

1 Manolopoulos KN, Karpe F, Frayn KN: Gluteofemoral body fat as a determinant of metabolic health. Int J Obes (Lond) 2010;34:949-959.

-2 Van Pelt RE, Evans EM, Schechtman KB, Ehsani AA, Kohrt WM: Contributions of total and regional fat mass to risk for cardiovascular disease in older women. Am J Physiol Endocrinol Metab 2002;282:E1023-1028

3 Tanko LB, Bagger YZ, Alexandersen P, Larsen PJ, Christiansen C: Peripheral adiposity exhibits an independent dominant antiatherogenic effect in elderly women. Circulation 2003;107:1626-1631.

4 Ferreira I, Snijder MB, Twisk JW, van Mechelen W, Kemper HC, Seidell JC, Stehouwer CD: Central fat mass versus peripheral fat and lean mass: opposite (adverse versus favorable) associations with arterial stiffness? The Amsterdam Growth and Health Longitudinal Study. J Clin Endocrinol Metab 2004;89:2632-2639.
5 Snijder MB, Visser M, Dekker JM, Goodpaster BH, Harris TB, Kritchevsky SB, De Rekeneire N, Kanaya AM, Newman AB, Tylavsky FA, Seidell JC: Low subcutaneous thigh fat is a risk factor for unfavourable glucose and lipid levels, independently of high abdominal fat. The Health ABC study. Diabetologia 2005;48:301-308.

6 Rotunda AM, Suzuki H, Moy RL, Kolodney MS Detergent effects of sodium deoxycholate are a major feature of an injectable phosphatidylcholine formulation used for localized fat dissolution. Dermatol Surg 2004;30:1001-1008.

7 Janke J, Engeli S, Gorzelniak K, Luft FC, Jordan $\mathrm{J}$ : Compounds used for 'injection lipolysis' destroy adipocytes and other cells found in adipose tissue. Obes Facts 2009;2:36-39.

8 Prado A, Andrades P, Danilla S, Leniz P, Castillo P, Gaete F: A prospective, randomized, doubleblind, controlled clinical trial comparing laserassisted lipoplasty with suction-assisted lipoplasty. Plast Reconstr Surg 2006;118:1032-1045. $\checkmark$ Adcock D, Paulsen S, Jabour K, Davis S, Nanney LB, Shack RB: Analysis of the effects of deep mechanical massage in the porcine model. Plast Reconstr Surg 2001;108:233-240.

10 Benelli L, Berta JL, Cannistra C, Amram P, Benhamou G: Endermologie: humoral repercussions and estrogen interaction. Aesthetic Plast Surg 1999; 23:312-315.

11 Moseley AL, Esplin M, Piller NB, Douglass J: Endermologie (with and without compression bandaging) - a new treatment option for secondary arm lymphedema. Lymphology 2007;40:129-137.

12 Ortonne JP, Queille-Roussel C, Duteil L, Emiliozzi C, Zartarian M: Treatment of cellulite: effectiveness and sustained effect at 6 months with Endermologie demonstrated by several quantitative evaluation methods. Nouv Dermatol 2004;3:13-50.

13 Chang P, Wiseman J, Jacoby T, Salisbury AV, Ersek RA: Noninvasive mechanical body contouring: (endermologie) a one-year clinical outcome study update. Aesthetic Plast Surg 1998;22:145-153. 
14 Kinney B: Endermologie ${ }^{\circledR}$ (the LPG ${ }^{\circledR}$ Technique) and cellulite: my clinical practice. J Cutan Laser Ther 2001;3:13-50.

15 Monteux C, Lafontan M: Use of the microdialysis technique to assess lipolytic responsiveness of femoral adipose tissue after 12 sessions of mechanical massage technique. J Eur Acad Dermatol Venereol 2008;22:1465-1470.

16 Kussmann M, Rezzi S, Daniel H: Profiling techniques in nutrition and health research. Curr Opin Biotechnol 2008;19:83-99.

17 Liu ET, Karuturi KR: Microarrays and clinical investigations. N Engl J Med 2004;350:1595-1597.

18 Viguerie N, Poitou C, Cancello R, Stich V, Clement K, Langin D: Transcriptomics applied to obesity and caloric restriction. Biochimie 2005;87:117-123.

19 Capel F, Klimcakova E, Viguerie N, Roussel B, Vitkova M, Kovacikova M, Polak J, Kovacova Z, Galitzky J, Maoret JJ, Hanacek J, Pers TH, Bouloumie A, Stich V, Langin D: Macrophages and adipocytes in human obesity: adipose tissue gene expression and insulin sensitivity during calorie restriction and weight stabilization. Diabetes 2009; 58:1558-1567.

20 Mutch DM, Temanni MR, Henegar C, Combes F, Pelloux V, Holst C, Sorensen TI, Astrup A, Martinez JA, Saris WH, Viguerie N, Langin D, Zucker JD, Clement K: Adipose gene expression prior to weight loss can differentiate and weakly predict dietary responders. PLoS One 2007;2:e1344.

-21 Karpe F, Fielding BA, Ilic V, Humphreys SM, Frayn KN: Monitoring adipose tissue blood flow in man: a comparison between the (133)xenon washout method and microdialysis. Int $\mathrm{J}$ Obes Relat Metab Disord 2002;26:1-5.

-22 Capel F, Viguerie N, Vega N, Dejean S, Arner P, Klimcakova E, Martinez JA, Saris WH, Holst C, Taylor M, Oppert JM, Sorensen TI, Clement K, Vidal H, Langin D: Contribution of energy restriction and macronutrient composition to changes in adipose tissue gene expression during dietary weight-loss programs in obese women. J Clin Endocrinol Metab 2008;93:4315-4322.

23 Tusher VG, Tibshirani R, Chu G: Significance analysis of microarrays applied to the ionizing radiation response. Proc Natl Acad Sci U S A 2001;98: 5116-5121.

24 Calvano SE, Xiao W, Richards DR, Felciano RM, Baker HV, Cho RJ, Chen RO, Brownstein BH, Cobb JP, Tschoeke SK, Miller-Graziano C, Moldawer LL, Mindrinos MN, Davis RW, Tompkins RG, Lowry SF: A network-based analysis of systemic inflammation in humans. Nature 2005;437: 1032-1037.

25 Stich V, de Glisezinski I, Berlan M, Bulow J, Galitzky J, Harant I, Suljkovicova H, Lafontan M, Riviere D, Crampes F: Adipose tissue lipolysis is increased during a repeated bout of aerobic exercise. J Appl Physiol 2000;88:1277-1283.
26 Moro C, Pillard F, de Glisezinski I, Klimcakova E, Crampes F, Thalamas C, Harant I, Marques MA, Lafontan M, Berlan M: Exercise-induced lipid mobilization in subcutaneous adipose tissue is mainly related to natriuretic peptides in overweight men. Am J Physiol Endocrinol Metab 2008;295:E505-513.

27 Bernst E, Gutmann I: Determination of ethanol with alcohol dehydrogenase and NAD; in Bergmeyer HU (ed): Methods of Enzymatic Analysis, vol 3. New York, Academic, 1974, pp 1499-1505.

28 Park SK, Prolla TA: Lessons learned from gene expression profile studies of aging and caloric restriction. Ageing Res Rev 2005;4:55-65.

29 Zagorski J, Obraztsova M, Gellar MA, Kline JA, Watts JA: Transcriptional changes in right ventricular tissues are enriched in the outflow tract compared with the apex during chronic pulmonary embolism in rats. Physiol Genomics 2009;39:61-71.

30 Prokopchuk O, Liu Y, Wang L, Wirth K, Schmidtbleicher D, Steinacker JM: Skeletal muscle IL-4, IL-4Ralpha, IL-13 and IL-13Ralpha1 expression and response to strength training. Exerc Immunol Rev 2007;13:67-75

-31 Viguerie N, Vidal H, Arner P, Holst C, Verdich C, Avizou S, Astrup A, Saris WH, Macdonald IA, Klimcakova E, Clement K, Martinez A, Hoffstedt J, Sorensen TI, Langin D: Adipose tissue gene expression in obese subjects during low-fat and highfat hypocaloric diets. Diabetologia 2005;48:123-131.

32 Lafontan M: Advances in adipose tissue metabolism. Int J Obes (Lond) 2008;32(suppl 7):S39-51.

33 Yen CL, Stone SJ, Koliwad S, Harris C, Farese RV Jr: Thematic review series: Glycerolipids. DGAT enzymes and triacylglycerol biosynthesis. J Lipid Res 2008;49:2283-2301.

34 Tanabe Y, Koga M, Saito M, Matsunaga Y, Nakayama K: Inhibition of adipocyte differentiation by mechanical stretching through ERK-mediated downregulation of PPARgamma2. J Cell Sci 2004; 117:3605-3614.

35 Christodoulides C, Lagathu C, Sethi JK, VidalPuig A: Adipogenesis and WNT signalling. Trends Endocrinol Metab 2009;20:16-24.

36 White UA, Stephens JM: Transcriptional factors that promote formation of white adipose tissue. Mol Cell Endocrinol 2010;318:10-14.

37 Spencer M, Yao-Borengasser A, Unal R, Rasouli N, Gurley CM, Zhu B, Peterson CA, Kern PA: Adipose tissue macrophages in insulin resistant subjects are associated with collagen VI, fibrosis and demonstrate alternative activation. Am J Physiol Endocrinol Metab 2010;299:E1016-1027.

38 Lafontan M, Langin D: Lipolysis and lipid mobilization in human adipose tissue. Prog Lipid Res 2009:48:275-297.
39 Silha JV, Krsek M, Sucharda P, Murphy LJ: Angiogenic factors are elevated in overweight and obese individuals. Int J Obes (Lond) 2005;29:1308-1314.

40 Bouloumie A, Drexler HC, Lafontan M, Busse R: Leptin, the product of OB gene, promotes angiogenesis. Circ Res 1998;83:1059-1066.

41 Cheriyath V, Hussein MA: Osteopontin, angiogenesis and multiple myeloma. Leukemia 2005;19: 2203-2205.

42 Hato T, Tabata M, Oike Y: The role of angiopoietin-like proteins in angiogenesis and metabolism. Trends Cardiovasc Med 2008;18:6-14.

43 Bülow J, Madsen J: Influence of blood flow on fatty acid mobilization from lipolytically active adipose tissue. Pflügers Arch 1981;390:169-174.

44 Moro C, Crampes F, Sengenes C, De Glisezinski I, Galitzky J, Thalamas C, Lafontan M, Berlan M: Atrial natriuretic peptide contributes to physiological control of lipid mobilization in humans. FASEB J 2004;18:908-910.

45 Hossain MG, Iwata T, Mizusawa N, Shima SW, Okutsu T, Ishimoto K, Yoshimoto K: Compressive force inhibits adipogenesis through COX-2mediated down-regulation of PPARgamma2 and C/EBPalpha. J Biosci Bioeng 2010;109:297-303.

46 Kook SH, Son YO, Choi KC, Lee HJ, Chung WT, Hwang IH, Lee JC: Cyclic mechanical stress suppresses myogenic differentiation of adult bovine satellite cells through activation of extracellular signal-regulated kinase. Mol Cell Biochem 2008; 309:133-141.

47 Barbe P, Stich V, Galitzky J, Kunesova M, Hainer $\mathrm{V}$, Lafontan M, Berlan M: In vivo increase in betaadrenergic lipolytic response in subcutaneous adipose tissue of obese subjects submitted to a hypocaloric diet. J Clin Endocrinol Metab 1997;82:6369.

48 Sengenes C, Stich V, Berlan M, Hejnova J, Lafontan M, Pariskova Z, Galitzky J: Increased lipolysis in adipose tissue and lipid mobilization to natriuretic peptides during low-calorie diet in obese women. Int J Obes Relat Metab Disord 2002;26:24-32.

49 Stich V, de Glisezinski I, Galitzky J, Hejnova J, Crampes F, Riviere D, Berlan M: Endurance training increases the beta-adrenergic lipolytic response in subcutaneous adipose tissue in obese subjects. Int J Obes Relat Metab Disord 1999;23:374-381.

50 Moro C, Pillard F, De Glisezinski I, Harant I, Riviere D, Stich V, Lafontan M, Crampes F, Berlan M: Training enhances ANP lipid-mobilizing action in adipose tissue of overweight men. Med Sci Sports Exerc 2005;37:1126-1132. 